\title{
Atos Ordinatórios e o Poder de Requisição da Autoridade Policial
}

Wellington Clay Porcino Silva ${ }^{1}$

\section{INTRODUÇÃo}

O presente trabalho tem como objetivo identificar, dentre os atos do Delegado de Polícia, na presidência do Inquérito Policial, quais podem ser considerados atos ordinatórios, bem como demonstrar o seu inequívoco poder-dever de requisição, apoiando-se para tanto na doutrina e jurisprudência.

Cabe esclarecer que muito pouco se estuda e publica a respeito da fase pré-processual da persecução criminal em geral ou mesmo sobre o Inquérito Policial em particular, em que pese a maioria esmagadora das ações penais em trâmite em nossas varas criminais ter como fundamento investigações formalizadas através desse importante instrumento.

\section{Classificação dos Atos Judiciais}

Tendo em vista a já mencionada lacuna da doutrina brasileira a respeito do Inquérito Policial, o presente artigo apoiarse-á, por analogia, na classificação dos atos judiciais no decorrer do processo penal.

1 Delegado de Polícia Federal, Mestre em Ciência e Sistemas de Informações Geográficas pela Universidade Nova de Lisboa; Doutorando em geografia pela UFRN. 
Assim, classificam-se os atos judiciais em atos ordinatórios ou atos decisórios. Segundo Oliveira (2005 p. 467):

“(...) há os atos em que o juiz simplesmente determina o seguimento do feito, dando cumprimento ao curso das fases procedimentais, sem se deter no exame de qualquer questão controvertida. São os chamados atos de impulso processual, notoriamente designados por despachos.

E há aqueles atos em que o juiz é chamado a resolver ponto ou questão sob os quais paire controvérsia relevante, seja sobre a pretensão de direito material (punitiva), seja também sobre matéria exclusivamente processual, relativa tanto aos pressupostos processuais, quanto às condições da ação. Temos aqui as decisões judiciais."

Os primeiros são denominados atos ordinatórios enquanto as decisões judiciais são classificadas como atos decisórios.

Em relação a essas últimas podemos ainda distingui-las como decisões interlocutórias e sentenças.

Assim, as três categorias de atos judiciais seriam, coincidindo perfeitamente com as estabelecidas no processo civil, as sentenças definitivas de mérito, absolvendo ou condenando; as decisões interlocutórias, decidindo questões incidentes de natureza processual e os despachos, cuidando de mero expediente (GRINOVER, et al., 2001).

A classificação acima dos atos judiciais tem relevância especialmente por impactar diretamente na natureza do recurso que desafiará cada tipo de decisão. Em relação aos atos ordinatórios, segundo a doutrina nacional, não cabe recurso, tão somente a utilização do instrumento de correição, para o controle do erro judicial em relação a questões procedimentais, das quais poderá resultar prejuízo para o feito (OLIVEIRA, 2005). 


\section{Atos do Delegado de Polícia.}

Em relação aos atos praticados por Delegado de Polícia no âmbito de um Inquérito Policial, a doutrina pouco se preocupa com o tema. Há, como já se disse, uma imensa lacuna a respeito de tão importante instrumento da persecução penal, que subsidia a quase totalidade das ações penais em curso hoje.

Desse modo, e diante de tal situação, utilizar-se-á, no presente trabalho, por analogia, a classificação acima exposta, pensada para os atos judiciais, adaptando-a às especificidades do trabalho do Delegado de Polícia.

Desse modo, portanto, podem-se entender como atos ordinatórios aqueles praticados pelo Delegado de Polícia, na presidência de Inquérito Policial, com o objetivo de permitir a regular instrução do feito sob sua responsabilidade.

Ou seja, são aqueles atos que objetivam dar curso à investigação, que dão impulso ao andamento do procedimento apuratório. Exemplifica-se: seriam os que resultariam na expedição de ofícios requisitando informações, realização de diligências pelos agentes da autoridade designados para tal, intimação de testemunhas, etc.

Já os atos decisórios, assim como os emitidos por autoridade judiciária, seriam aqueles destinados a resolver controvérsias. Quando transportamos este conceito para a realidade do Inquérito Policial, identificamos o ato decisório do Inquérito Policial em sua essência, aquele que poderia ser comparado a sentença de mérito, por óbvio, com os limites de cognição impostos a esse instrumento de persecução penal, qual seja, o indiciamento.

O indiciamento encontra previsão legal no art. $2^{\circ}, \S 6^{\circ}$ da lei $12.830 / 13$, in verbis: 
"§ 60 O indiciamento, privativo do Delegado de Polícia, dar-se-á por ato fundamentado, mediante análise técnico-jurídica do fato, que deverá indicar a autoria, materialidade e suas circunstâncias."

O indiciamento é o ato do Delegado de Polícia que conclui haver materialidade e indícios de autoria suficientes para imputar, ainda que em momento de cognição estreita, à determinada pessoa a autoria de um crime.

É o momento crucial de toda a investigação, aquele ato em que se consubstancia, de maneira fundamentada, a identificação da materialidade e da autoria, objetivo fim da persecução penal extra iudicio.

Podemos, ainda, apontar como ato decisório do Delegado de Polícia a determinação de afastamento de servidor público decorrente de seu indiciamento por lavagem de dinheiro, nos termos do art. 17-D da Lei n⿳⺈ 9.613/98.

Contudo, todos os atos do Delegado de Polícia no corpo de um Inquérito Policial são denominados ordinariamente de despacho, independente de seu caráter decisório ou não, ao contrário do que ocorre em relação aos atos judiciais.

Assim, pode ocorrer de em um único despacho haver conteúdo decisório e ordinatório, como ocorre no despacho que ao mesmo tempo determina o recolhimento de conduzido apresentado ao Delegado de Polícia, quando este reconhece presentes os requisitos da prisão em flagrante, ato claramente decisório, e determina a elaboração da ficha de informações criminais, ato de mero seguimento. 


\section{O Poder de Requisição do Delegado de Polícia}

Dentre os atos ordinatórios praticados por Delegado de Polícia na instrução de um Inquérito Policial, interessa mais detidamente a este trabalho a requisição de dados e informações de interesse à elucidação dos fatos sob exame.

Tal poder, embora necessário ao exercício do poder-dever de investigar da polícia judiciária, insculpido no art. $144 \S 1^{\circ}$, I e IV, em relação à Polícia Federal e $\S 4^{\circ}$, no que toca às Polícias Civis, todos da Constituição Federal, já foi objeto de inúmeras discussões, já que inexistia previsão expressa em norma legal.

Embora houvesse esta lacuna legal, o melhor entendimento sempre foi no sentido da existência de poder de requisição amplo durante a investigação policial.

Não poderia ser outra a conclusão diante do art. $6^{0}$ do Código de Processo Penal, que determina, em seu inciso III que o Delegado de Polícia deverá "colher todas as provas que servirem para o esclarecimento do fato e suas circunstâncias".

Ora, não pode ser outro entendimento então, que no exercício do seu poder-dever de apurar a infração penal, deve o Delegado de Polícia requisitar informações detidas por particular ou órgão público. Tal poder somente encontra limite quando houver cláusula de reserva de jurisdição, isto é, no caso de dados ou informações que afetem de tal modo a intimidade do cidadão que a norma atribui ao Poder Judiciário, de forma exclusiva, a decisão sobre o seu acesso, como é o caso do sigilo bancário de particular.

Assim é forçoso reconhecer a existência de um Poder Geral de Polícia (FELDENS, 2004), isto é, o poder-dever de executar todos os atos necessários à apuração da autoria e materialidade do fato criminoso objeto do Inquérito Policial. 
É justamente a existência desse poder que já fundamentava, desde a publicação do Código de Processo Penal, o poder de requisição do Delegado de Polícia, pois, se tal autoridade deve colher todas as provas necessárias ao esclarecimento do fato, tem obrigação de requisitar as informações de interesse da investigação que terceiros possuírem.

Contudo, para sepultar discussões doutrinárias que não reconheciam a existem do Poder Geral de Polícia como um todo e do poder de requisição do Delegado de Polícia, ignorando a hermenêutica básica da legislação processual penal em vigor, editou-se a lei 12.830/13, que expressamente prevê, em seu art. $2^{\circ}, \S 1^{\circ}$, o poder de requisição do Delegado de Polícia.

Segue abaixo o dispositivo legal, in verbis:

"Art. 2o (...)

$\S 10$ Durante a investigação criminal, cabe ao Delegado de Polícia a requisição de perícia, informações, documentos e dados que interessem à apuração dos fatos."

Neste mesmo sentido, cita-se a posição de Jeferson Botelho Pereira (2013), conforme exposta por Francisco Sannini Neto e Eduardo Luiz Santos Cabette (2014):

“O sobredito poder requisitório permite à Autoridade Policial adotar todas as providências que se fizerem necessárias à coleta das provas, para a mais breve e salutar elucidação dos fatos em apuração, podendo assim requisitar a particulares, a agentes públicos, bem como a estabelecimentos públicos ou privados o auxílio necessário à identificação e instrumentalização das provas, a exemplo, da requisição de imagens registradas por circuito interno de gravação próprio e de informações não acobertadas por sigilo legal, materializando-as na investigação policial."

Desse modo, encontra-se superada a discussão sobre a existência ou não do poder de requisição do Delegado de Polícia. 
Contudo, uma vez superada a fase de discussão sobre a existência desse poder-dever, discute-se, atualmente, a sua extensão, ou seja, quais dados podem ser requisitados pela autoridade policial diretamente e quais dependeriam de prévia autorização judicial.

E quais seriam estes dados com proteção especial? Cita-se a seguir o posicionamento de Renata da Silva Rodrigues (2016 p. 272):

A chamada "reserva de jurisdição", de ordem constitucional, impõe que três medidas sejam necessariamente objeto de controle jurisdicional prévio: a busca domiciliar sem autorização do proprietário (CF, art. $5^{\circ}$, XI). A quebra do sigilo da comunicação de dados e comunicação telefônica (CF, art. 5으, XII) e a decretação da prisão de qualquer pessoa, ressalvada a hipótese de flagrância (CF, art. $5^{\circ}$, LXI). No ordenamento infraconstitucional, também se encontram previsões esparsas acerca de determinadas medidas que dependem de autorização judicial, tais como a ação controlada (Lei 11.343/06), a obtenção de registro de conexão e de acesso a aplicações de internet (Lei 12.965/14) e a quebra do sigilo fiscal (art. $1^{\stackrel{0}{ }}$,

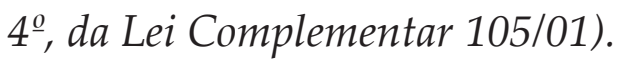

Desse modo, e tendo em vista o caráter administrativo da atividade de polícia judiciária, as requisições feitas por um Delegado de Polícia no exercício de seu mister investigativo, como regra geral, não são submetidas a uma prévia análise por parte do poder judiciário, tendo em vista a autoexecutoriedade dos atos administrativos. Contudo, diante de previsão expressa na legislação pátria, torna-se necessária para a requisição de determinados dados e informações prévia autorização judicial.

Neste sentido:

(...) Não se constata ilegalidade no proceder policial, que requereu à operadora de telefonia móvel responsável pela Estação Rádio-Base o registro dos telefones que utilizaram o serviço na localidade, em dia e hora da prática do crime. 4. 
A autoridade policial atuou no exercício do seu mister constitucional, figurando a diligência dentre outras realizadas ao longo de quase 7 (sete) anos de investigação. 5. Ademais, eventuais excessos praticados com os registros logrados podem ser submetidos posteriormente ao controle judicial, a fim de se verificar qualquer achincalhe ao regramento normativo pátrio. 6. In casu, a autoridade policial não solicitou à operadora de telefonia o rol dos proprietários das linhas telefônicas ou o teor do colóquio dos interlocutores, apenas os numerários que utilizaram a Estação de Rádio-Base na região, em período adstrito ao lapso delitivo, não carecendo de anterior decisão judicial para tanto, sobressaindo, inclusive, a necessidade da medida policial adotada, que delimitou a solicitação para a quebra do sigilo das conversas dos interlocutores dos telefones e da identificação dos números que os contactaram, feita perante o Juizo competente, que aquiesceu com a obtenção do requestado. (...) (STF, Processo: HC 124322/RS, Rel: Min. Roberto Barroso, Julgamento: 29/10/2014, Publicação DJe-216 DIVULG 03/11/2014 PUBLIC 04/11/2014).

O acordão acima citado pontua outra questão relevante, em relação aos limites do poder de requisição do Delegado de Polícia. Ainda hoje podemos identificar, claramente, que há grande resistência nas operadoras de telefonia em fornecerem informações referentes aos dados cadastrais de usuários de determinada linha telefônica, o histórico de chamadas e, ainda, informações a respeito das linhas que utilizaram, em determinado período de tempo, uma estação rádio base (ERB) específica.

Ora, tais informações são extremamente relevantes em uma investigação policial, podendo, muitas vezes, serem suficientes para a identificação do autor de determinado delito. No entanto, por reiteradas vezes, concessionárias de serviço público de telefonia se negam a fornecê-las aos delegados de polícia, alegando estarem tais dados protegidos pelo sigilo de comunicações telefônicas e, portanto, sujeitos à cláusula de reserva de jurisdição. 
Porém, tal entendimento não poderia estar mais equivocado. Se estivessem tais dados sujeitos à reserva de jurisdição, de natureza constitucional, como poderiam leis ordinárias determinar o fornecimento de dados cadastrais requisitados por delegados de polícia? É exatamente o que fazem duas das mais importantes leis penais recentemente publicadas: a Lei no 9.613/98, que tipifica o crime de lavagem de dinheiro, com a nova redação dada pela Lei $n^{\mathrm{o}}$ 12.683/12 e a Lei $\mathrm{n}^{\mathrm{o}}$ 12.850/13, lei de combate ao crime organizado.

A Lei $n^{0}$ 9.613/98, em seu art. 17-B, assim determina:

Art. 17-B A Autoridade Policial e o Ministério Público terão acesso, exclusivamente, aos dados cadastrais do investigado que informam qualificação pessoal, filiação e endereço, independentemente de autorização judicial, mantidos pela Justiça Eleitoral, pelas empresas telefônicas, pelas instituições financeiras, pelos provedores de internet e pelas administradoras de cartão de crédito.

A Lei $\mathrm{n}^{\mathrm{o}}$ 12.850/13 prescreve, em seu art. 15, o que se segue: Art. 15 O Delegado de Polícia e o Ministério Público terão acesso, independentemente de autorização judicial, apenas aos dados cadastrais do investigado que informem exclusivamente a qualificação pessoal, a filiação e o endereço mantidos na Justiça Eleitoral, empresas telefônicas, instituições financeiras, provedores de internet e administradoras de cartão de crédito.

Desse modo, se existe permissivo legal, por meio de lei ordinária para a requisição de dados cadastrais nas investigações dos crimes acima mencionados, é porque tais informações não estão protegidas pela reserva de jurisdição. E se não estão também previstas como informações protegidas por sigilo judicial em leis esparsas, devem ser fornecidas sempre que requisitadas por Delegado de Polícia independente do delito investigado. 
Aplica-se, neste caso, o Poder Geral de Polícia, previsto no art. 6º , III do Código de Processo Penal.

No acordão do Pretório Excelso acima transcrito verificase, além do reconhecimento do Poder Geral de Polícia, de forma inequívoca, que o acesso do Delegado de Polícia aos dados referentes às linhas de telefone que se utilizaram de determinada ERB em um determinado período de tempo são passíveis de requisição por Delegado de Polícia, mais uma vez reforçando os argumentos acima expostos.

Neste mesmo sentido, seguem acórdãos do Superior Tribunal de Justiça, reconhecendo o poder de requisição do Delegado de Polícia, e decidindo a sua extensão, inclusive em relação aos dados cadastrais e às informações de ERB:

O teor das comunicações efetuadas pelo telefone e os dados transmitidos por via telefônica são abrangidos pela invio-

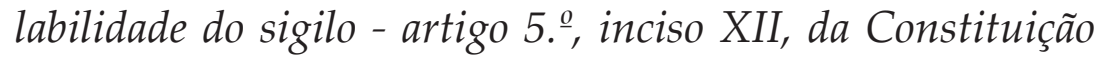
Federal -, sendo indispensável a prévia autorização judicial para a sua quebra, o que não ocorre no que tange aos dados cadastrais, externos ao conteúdo das transmissões telemáticas. Não se constata ilegalidade no proceder policial, que requereu à operadora de telefonia móvel responsável pela Estação Rádio-Base o registro dos telefones que utilizaram o serviço na localidade, em dia e hora da prática do crime. A autoridade policial atuou no exercício do seu mister constitucional, figurando a diligência dentre outras realizadas ao longo de quase 7 (sete) anos de investigação. (HC 247331/ RS, Rel. Min. Maria Thereza de Assis Moura, 6‥ Turma, DJ 21.08.2014, DJe 03.09.2014).

Não há ilegalidade na quebra do sigilo de dados cadastrais de linhas telefônicas os quais, conforme o tribunal de origem, foram obtidos por autoridade policial que recebeu de magistrado senha fornecida pela Corregedoria de Polícia Judiciária. Isso porque, conforme entendimentos do STF e do STJ, o disposto no artigo $5^{\circ}$, XII, da CF não impede o acesso aos dados 
em si, ou seja, o objeto protegido pelo direito à inviolabilidade do sigilo não são os dados em si, mas tão somente a comunicação desses dados. O entendimento do tribunal de origem é que sobre os dados cadastrais de linhas telefônicas inexiste previsão constitucional ou legal de sigilo, já que não fazem parte da intimidade da pessoa, assim como sobre eles não paira o princípio da reserva jurisdicional. Tal entendimento está em consonância com a jurisprudência do STJ. (AgReg no HC 181546/SP, Rel. Min. Marco Aurélio Bellizze, 5ª. Turma, DJ 11.02.2014, DJe 18.02.2014).

Utilizando-se o raciocínio acima exposto, isto é, que somente a comunicação em si está abarcada pela reserva de jurisdição, e não os dados referentes a esta comunicação, diante da inexistência de impeditivo constitucional ou legal, também não existe como se negar acesso, ao Delegado de Polícia, aos históricos de ligações efetuadas por determinado investigado.

Ora, o número chamado e o tempo de ligação são, tão somente, dados referentes a comunicação, nada relevando a respeito da comunicação em si.

Portanto, tais informações devem ser fornecidas ao Delegado de Polícia, independente de ordem judicial, sempre que requisitadas, já que não possuem qualquer sigilo especial.

Ressalte-se que não está se afirmando que tais dados são públicos. Claro que não. Tais dados são de fato de acesso restrito, não podendo serem fornecidos a qualquer do povo que os solicite.

Contudo, tal restrição deve ceder face o interesse público de identificação de autoria e materialidade de uma infração penal, em uma investigação presidida por Delegado de Polícia, já que esta autoridade tem o poder-dever de apuração dos delitos e, que tal medida se encontra amparada não só na legislação penal pátria, mas também em vasta jurisprudência que reconhece, de forma unânime, o Poder Geral de Polícia, isto é, a capacidade do Delegado de Polícia executar todas as diligências, inclusive 
expedição de requisições, que forem do interesse da investigação em curso, desde que não vedadas pelo ordenamento jurídico.

Tais argumentos também derrubam as alegações falaciosas de operadoras de telefonia que procuram escudar suas negativas na Lei no 9.472/97 que em seu art. 3ํ, V, reconhece ao usuário o direito à não publicização de seu código de acesso (número de telefone), ou ainda na Lei $\mathrm{n}^{\mathrm{o}}$ 10.703/03, que em seu art. $1^{\circ}$, § 3 , estabelece o respeito à privacidade do usuário nos serviços de cobrança e na utilização dos dados pela operadora.

O que os dispositivos legais buscam impedir é o uso comercial dos dados dos clientes pelas operadoras e não o acesso de autoridade pública em seu mister previsto constitucionalmente, amparado ainda em previsão legal específica, como é o caso da requisição por Delegado de Polícia.

Neste mesmo sentido, pode-se mencionar Rodrigues (2016).

Repete-se, atender à requisição do Delegado de Polícia não é tornar público o dado. É tão somente permitir que o Estado Investigação tenha acesso a informações relevantes para a apuração de materialidade e autoria de delito penal, no estrito cumprimento das normas legais pátrias.

\section{Conclusão}

Como se demonstrou no presente texto, o poder de requisição do Delegado de Polícia não só possui expressa previsão legal, como também é decorrente do Poder Geral de Polícia, conforme prescreve o art. $6^{\circ}$, III, do Código de Processo Penal, poder este de matriz constitucional, pois é através dele que o Estado Investigação, através das polícias judiciárias federal e estaduais, pode atingir seu fim constitucional, ou seja, a apuração das infrações penais. 


\section{REFERÊNCIAS BibLIOGRÁfICAS}

FELDENS, Luciano. UOL [Online] // Última instância. - 2004. 25 de outubro de 2016. - http://ultimainstancia.uol.com.br/ conteudo/colunas/130/poder+geral+de+policia+e+sigilo+te lefonico.shtml.

GRINOVER, Ada Pelegrini; GOMES FILHO, Antônio Magalhães; e FERNANDES, Antônio Scarance. Recursos no Processo Penal: teoria geral dos recursos, recursos em espécie, ações de impugnação - habeas corpus, revisão criminal,e mandado de segurança contra ato jurisdicional penal, reclamação aos tribunais [Livro]. - São Paulo : RT, 2001.

SANNINI NETO, Francisco; e CABETTE, Eduardo Luiz Santos. Jus Navigandi [Online] // Jus Navigandi. - Jus Navigandi, 22 de 09 de 2014. - 26 de 10 de 2016. - https://jus.com.br/ artigos/32089.

OLIVEIRA, Eugênio Pacelli de. Curso de Processo Penal [Livro]. Belo Horizonte : Del Rey, 2005.

PEREIRA, Jeferson Botelho. Lei n.$^{\circ}$ 12.830/2013: as garantias do Delegado de Polícia. [Online] // Jus Navigandi. - Jus Navigandi, 27 de 06 de 2013. - 26 de 10 de 2016. - http:// jus.com.br/artigos/24795.

RODRIGUES, Renata da Silva. O Poder de Requisição de Dados Telefônicos pela Autoridade Policial: uma breve análise do ordenamento jurídico e revisão jurisprudencial [Seção do Livro] // Temas Processuais da Atualidade: doutrina e prática / A. do livro BEZERRA Clayton da Silva e AGNOLETTO Giovani Celso (orgs.). - Rio de Janeiro : Letras Jurídicas, 2016. 